\title{
Chinese E-commerce Taxation
}

\author{
Maoliang Zhang \\ Shaanxi Provincial Administration College, Xi'an, Shaanxi \\ ZhangmL6206@163.com
}

Keywords: E-commerce; Growth; Tax loss; Turnover tax; Electronic invoice

\begin{abstract}
With the popularity of the Internet and the maturity of network financial, e-commerce sweep streets. Everyone knows Taobao, Jingdong and other names and more and more people open shops on the Internet.But because China still lacks system e-commerce tax policy theory" this blank makes a serious tax loss.

According to Commerce Department statistics, in the first three quarters of 2014, e-commerce transactions amount to 8.6 trillion, and the estimated annual turnover will be more than 12 trillion, an increase of over $20 \%$. Almost half of the growth of thanks to the online shopping, which becomes an important force to promote e-commerce in the market development. China Electronic Commerce Research Center data shows that US online retail sales in 2013 amounted to \$ 262 billion, China has surpassed the US to become the world's largest online trading market. In 2013, China's online shopping users reached 302 million, an increase of $24.7 \%$ contrast to last year. And our e-commerce transactions exceeded 10 trillion, an increase of $26.8 \%$ contrast to last year. Among them, the online retail market turnover exceed 1.85 trillion, an increase of $41.2 \%$, and reach the proportion of total social consumer goods retail to $7.8 \%$.According to a research, $97.5 \%$ people knows the e-commerce, and $45 \%$ people shopping online always. However, there are only $12.5 \%$ people knows about the taxation of e-commerce. (Show as below)
\end{abstract}

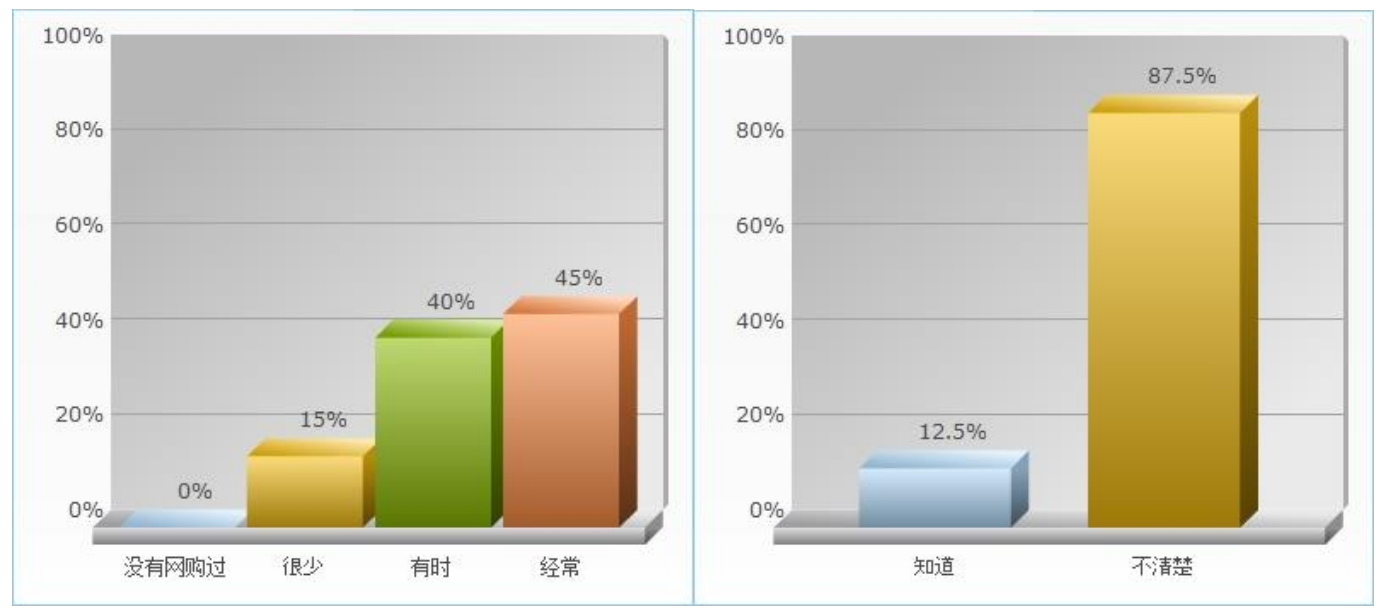

Figure. 1 Overview of e-commerce

Currently there are three main forms of e-commerce, which are B-B ( business to business ), B-C ( business to consumer) and C-C ( user-to- user ). Although China neither has a new e-commerce tax , nor special laws and policies, the current tax system is still effective in. B-B mode and B-C mode. But because these two modes mainly calculate and collect taxes in accordance to the existing 
turnover tax rules, in the implementation process there will be many problems such as the determination of taxation elements, the division of tax jurisdiction and other issues. However,everyone seems to ignore the taxation of the most widely used e-commerce C-C mode . Last year, the chairman of suning,Zhang Jindong, argued that " The electronic business platform can sell fakes, can Suning sell it? You can pay no taxes on electronic business platform , can Suning not pay it? "Even Alibaba CEO Jack Ma also acknowledged that " sooner or later the electronic commerce is to pay taxes."

\section{Some basic principles should be followed in ecommerce taxation}

Firstly, because the B-B mode and B-C mode is taxed in accordance with current traditional way of turnover tax, governments should consider the characteristics of e-commerce and make the necessary modifications to the existing tax system. At present, the turnover tax system in our country contains added-value tax, consumption tax, business tax and tariffs. And electronic commerce enterprise mainly related to the consumption tax. China's consumption tax is the tax inclusive price, and the consumption tax of ordinary goods is calculated as: consumption tax payable $=$ excluding VAT sales income $(\mathrm{SI}) *$ consumption tax rate $(\mathrm{R})$. Consumption tax for imported goods: consumption tax $=$ (price + tariff $) *$ consumption tax rate / (1- consumption tax rate). To accuratly calculate and collect consumption tax from e-commerce suppliers, authorized sales is the key. Secondly, many BC model shop mix in CC mode sites to intentional or unintentional evade tax, which cause a lot of tax losses. Thirdly, it is also important to maintain the neutrality of tax principle, different business forms can't have different tax principle. In addition, to encourage the development of new technology, it isn't a good idea to product a new tax on e-commerce supplier, which will lead a discriminate against electricity supplier taxation and is not conducive to the development of the Internet economy. Finally, the tax policy and tax collection should combined and the tax police should be established in the possible level of tax collection, making the tax policy can actualized smoothly and accurately .

\section{What can we learn from international cases?}

The first case is to talk about the leader of e-commerce, the United States, whose e-commerce companies account for about one-third of the word. In 2013, the US Senate pass the "2013 Market Equity Act," the bill is the United States' first nationwide Internet consumption tax proposal. The bill allows the government collect taxes from e-commerce suppliers across regions. Other countries like Australia, also requires e-commerce suppliers have identification numbers, proper registration procedures and complete electronic data. Australia has been taxing the e-commerce supplier the same as entity stores. After shopping online, buyers will receive a receipt from the e-commerce suppliers, which conclude the government tax receipts. Our neighbor Korea, shopping online and shopping in malls are treated the same in the tax standard. In addition to the basic tax, suppliers also need to pay $10 \%$ VAT. Besides, according to Japanese media reports, Japan has decided the outline of 2015 fiscal tax reform. Since October, purchasing e-books overseas and other music services through the Internet will be levied consumption tax. Under the new system, no matter where the enterprise is, as long as the purchaser is domestic, all taxes will be imposed. The general practice is adding the consumption tax to the price of goods and transfer to consumers. 


\section{Figure4. The current situation}

In January 5th, the State Council Legislative Affairs Office published the "People's Republic of China Administration of Tax Collection Law Amendment Bill (draft)". Several chapters of the draft increase contents of the tax on online transactions, which attract the close attention of all parties. Of which, the article 19, says: Taxpayers engaged in online transactions should prominently posted the information of tax registration or electronic link logo on its website home page. Article 33 requires the e-commerce trading platforms to provide the tax registration informations of traders. On the issue of e-commerce suppliers' taxation, the Central Financial Work Leading Group assigned tasks to ministries last year. The State Administration of Taxation led and do some related researches of e-commerce tax collection. The tax department never had a tax-free meaning on e-commerce suppliers, but always stressed that the issue of taxation only needs time. By all accounts, tax on e-commerce suppliers is already on the table.

\section{Figure5. Summary}

China has carried out a comprehensive electronic invoice and electronic accounting records pilot, suppliers can issue for public reimbursable electronic invoice, and succeeded in reimbursement electronically recorded. Electronic invoices apply electronic management. The e-commerce suppliers sell a product and issue electronic invoices at the time of the transaction completed, then all data will be passed back to the tax authorities. The background system of the state taxation administration will receive information, which greatly reduce the workload and difficulty of collection. Besides, the tax authorities can achieve real-time monitoring of all.

At present, e-commerce companies gradually introduced electronic invoices in the north, east, southwest and southern regions in China. It is expected to promote over the country in 2015, and establishing supportive electronic business tax collection system. In the joint effort of the tax department and the e-commerce enterprises, the use of electronic invoice is gradually expanding. Jingdong has issued about 20 million electronic invoices, primarily introducing in the North, East and Southwest. Electronic invoice will also be on-line in August in South China. Millet, Oriental Shopping, One shop and many other e-commerce suppliers also begin to use electronic invoices. However, only in special area canelectronic invoice be used.

\section{References}

[1] Xiaoyan Zhang. On the China B2C e-commerce development thinking to explore [J] market modernization in September.2005 (in total), 443rd.

[2]Jian Wang, JiaLin Fang, comparison and Enlightenment of the United States and Japan, Europe and the development of modern logistics, Northeast Asia Forum, 200502

[3] Jingwei Liu; RongSun; Weidong Kou, State Key Laboratory of Integrated Service Networks; Xidian University; $\mathrm{Xi}^{\vee}$ an 710071; Shaanxi; China;

[4]Electronic commerce development planning at the national development and Reform Commission, the State Council Information Office, 2007

[5]Chan Yang; the taxation problems of e-commerce activities and strategies "triggered response of commercial culture (first half)" in 20112011 the 04 period) 
[6]Hongbo Jiang; [J] problem of tax administration and Its Countermeasures of electronic commerce; Canada; the 20 phase of 2010

[7]Huifei Lu; electronic signature: on e-commerce and e-government, the last one kilometer Chinese tax report; [N]; 2010

[8]Fengrong Zhai, The Present Situation of China's E-commerce and Its Future Development Journal of Yantai University Journal of Yantai University.

[9]Culture. The traditional enterprise electronic commerce [J]. Guangdong financial college newspaper, 2006 (3).

[10]Under the environment of electronic commerce tax , economist, 2007/01. 